\title{
Pengaruh metode latihan dan agility terhadap keterampilan sepakbola
}

\author{
Prahastara Prahastara a *, FX. Sugiyanto ${ }^{b}$ \\ Universitas Negeri Yogyakarta. Jl. Colombo No.1 Yogyakarta 55281. Indonesia \\ a prahastara@gmail.com,b fx.sugiyanto56@gmail.com \\ * Coressponding Author.
}

Received: 15 January 2021; Revised: 30 January 2021; Accepted: 16 February 2021

\begin{abstract}
Abstrak: Penelitian ini bertujuan untuk membandingkan metode latihan drill dan small sided games terhadap keterampilan sepakbola, perbedaan keterampilan sepakbola siswa agility tinggi dan siswa agility rendah, serta interaksi metode latihan dan agility terhadap keterampilan sepakbola. Penelitian ini merupakan eksperimen faktorial $2 \times 2$, dengan pretest dan posttest. Teknik pengambilan sampel dengan purposive sampling sebanyak 60 siswa. Instrumen untuk mengukur agility siswa ekstrakurikuler adalah Illinois Agility Test, validitas 0,95 dan realibilitas 0,78. Instrumen untuk mengukur keterampilan sepakbola adalah Ball Technique the David Lee Soccer Potential Circuit Test dengan validitas 0,73 dan realibilitas 0,8. Analisis data menggunakan ANAVA dua jalur yang dilanjutkan dengan Post-Hoc Tests pada taraf signifikansi $\alpha=0,05$. Hasil penelitian menunjukkan ada perbedaan pengaruh metode latihan drill dan small sided games terhadap keterampilan sepakbola, $\mathrm{p}=0,002<0,05$, ada perbedaan keterampilan sepakbola siswa yang memiliki agility tinggi dan agility rendah, $\mathrm{p}=0,000$ $<0,05$, ada interaksi metode latihan dan agility terhadap keterampilan sepakbola, $p=0,000<0,05$. Siswa yang memiliki agility tinggi lebih tepat dilatih dengan metode drill, sedangkan siswa agility rendah lebih tepat dilatih dengan metode small sided games.
\end{abstract}

Kata Kunci: metode latihan, drill, small sided games, agility, keterampilan sepakbola

\section{The effect of training method and agility on football skills}

Abstract: This research aims to reveal the differences between the effects of drill training method and small sided-game on football skills, the different of football skills in high agility and low agility students, and the interaction of exercise and agility and football skills. This research is an experimental study with a $2 \times 2$ factorial design, with the pretest and posttest. Sampling technique using the purposive sampling of 60 students. The instrument to measure the level of students' agility used Illinois Agility Test, with the validity of 0.95 and the reliability of 0.78. The instruments to measure football skills used Ball Technique the David Lee Soccer Potential Circuit Test with the validity of 0.73 and the reliability of 0.8. The data were analyzed using the ANAVA followed by Post-Hoc Tests at the significance level $\alpha=0.05$. The research result shows that there are differences in the effects of drill and small-sided games training method on football skills, $p=0.002<0.05$, there are differences in the effects of football skills on students with high agility and those with low agility, $p=0.000<0.05$, and there is an interaction of training methods and agility and football skills, $p=0.000>0.05$. The students with high agility are more appropriately trained using drill method, while those with lower agility are more appropriately trained using the small-sided games method.

Keywords: training method, drill, small sided games, agility, football skills

How to Cite: Prahastara, P., \& Sugiyanto, F. (2021). Pengaruh metode latihan dan agility terhadap keterampilan sepakbola. Sepakbola, 1(1), 23-31. doi:http://dx.doi.org/10.33292/sepakbola.v1i1.94

\section{PENDAHULUAN}

Setiap cabang olahraga memiliki karakteristik yang spesifik, oleh karena itu pembinaan olahraga dan program pelatihan harus menyediakan metode yang dapat diandalkan bagi pelatih olahraga tim untuk meningkatkan kualitas pelatihan sekaligus meningkatkan kinerja pemain. 
Secara tradisional, perkembangan pengetahuan dalam metode pelatihan olahraga tim telah menekankan pelatihan indeks kebugaran fisiologis tertentu, keterampilan persepsual, dan tindakan teknis atau taktis melalui penggunaan latihan berulang yang sering dilakukan dalam isolasi dari konteks kinerja kompetitif (Tessitore et al., 2006). Karakteristik cabang olahraga sepakbola merupakan permainan tim yang dilakukan dengan kerjasama antar pemain, maka teknik dasar bermain sepakbola menjadi hal yang sangat penting untuk melakukan kerjasama antar pemain. Sebagian besar pekerjaan, dari perspektif yang berpusat pada organisme, telah berfokus pada manfaat dari meningkatnya kompleksitas dan ketidakpastian adaptasi bagi individu dalam lingkungan pelatihan melalui efek interferensi kontekstual dan memberikan ringkasan atau umpan balik (Davids et al., 2013). Teori yang berpusat pada organisme menggambarkan pelatihan dengan metode tradisional ini sebagai mengarah pada peningkatan pengayaan representasi gerakan yang terinternalisasi (Davids et al., 2012).

Salah satu bentuk dari pelatihan tradisional dalam sepakbola adalah metode drill (Little \& Williams, 2006; Tessitore et al., 2006; Kelly et al., 2013) yang dicirikan dalam pelatihan bagiantugas dan instruksi adaptif (Wickens, 1989). Latihan dengan menggunakan metode drill lebih menekankan pada pengulangan gerakan pada keterampilan teknik dasar agar tercipta otomatisasi gerakan. Latihan drill yang dilakukan mengharuskan pengaturan giliran untuk melakukan gerakan latihan, dikarenakan jumlah bola lebih sedikit daripada jumlah siswa. Sehingga hanya melibatkan beberapa siswa saja tanpa melibatkan langsung seluruh siswa untuk melakukan suatu gerakan latihan keterampilan. Martens (2004), menyatakan metode tradisional lebih mengarah pada gaya berlatih yang didominasi oleh pelatih, sehingga peserta latihan lebih pasif dan menunggu. Pelatih memberikan contoh atau memberikan aba-aba melakukan teknik dasar sepakbola kemudian siswa mengikuti contoh atau aba-aba dari pelatih. Hal tersebut akan menyebabkan terhambatnya pencapaian penguasaan keterampilan dalam proses latihan oleh peserta karena banyak waktu yang terbuang akibat peserta menunggu giliran untuk melakukan latihan keterampilan. Meskipun dianggap lebih terfokus pada metode pelatihan yang terpusat pada pelatih, secara praktik, metode drill secara efektif dalam meningkatkan variabel fisik (Kelly et al., 2013) (Arslan et al., 2020), terutama pada komponen kelincahan (Chaalali et al., 2016).

Meskipun variabel fisik telah menjadi fokus utama dalam penelitian olahraga, sepakbola modern mengutamakan kolektivitas dalam bermain, apabila pemain mempunyai teknik bermain yang baik akan menghasilkan kerjasama dalam tim yang baik (Yang et al., 2018). Sebagai imbas dari perkembangan permaianan ini, program pelatihan dikembangkan berdasarkan situasi yang terjadi dalam pertandingan sepakbola (Machado et al., 2019; Arslan et al., 2020; Bonney et al., 2020). Pelatih yang menggunakan metode small-sided games (SSG) memberikan latihan keterampilan sepakbola dalam bentuk hampir sama dengan situasi permainan yang sesungguhnya dalam pertandingan sepakbola dan melibatkan seluruh pemain dalam suatu bentuk latihan. SSG memberikan dampak pada meningkatnya akuisisi gerakan dan keterampilan dalam membuat keputusan (Davids et al., 2013), meningkatkan kemampuan teknis dan kelincahan (agility) (Young \& Rogers, 2014) dengan kenyamanan yang lebih besar dalam melakukannya (Arslan et al., 2020). Selain bermanfaat dalam varialbel fisik dan teknik, metode pelatihan SSG terutama dimanfaatkan dalam meningkatkan keterampilan taktikal (Castelão et al., 2014; Sarmento et al., 2018; Machado et al., 2019). Dengan manfaat yang lebih komprehensif, metode pelatihan memang lebih sering direkomendasikan dari pada metode pelatihan drill.

Upaya untuk melaksanakan kegiatan pelatihan sepakbola tentu memerlukan alasan yang logis dari seorang pelatih dalam upaya pengembangan metode latihan. Penggunaan metode latihan yang tepat sangat diperlukan agar siswa dapat memahami dan menguasai teknik dasar permainan sepakbola, selain itu yang terpenting adalah siswa tetap mengikuti latihan dengan sungguh-sungguh untuk hasil latihan yang optimal. Hasil penelitian terdahulu telah menunjukkan bahwa baik metode pelatihan small-sided games (SSG) (Hristovski et al., 2011; Davids et al., 2013; Folgado et al., 2019) maupun drill (tradisional) (Tessitore et al., 2006; Kelly et al., 2013) telah digunakan dalam pengembangan performa pemain di berbagai kelompok usia.

Namun, berdasarkan pengamatan pada latihan di lapangan yang menggunakan metode SSG, siswa yang memiliki keterampilan gerak kurang baik, kesulitan dalam menerapkan prosedur metode SSG dan mendapatkan kesempatan yang lebih sedikit untuk melakukan keterampilan 
dengan bola karena siswa jarang mendapatkan sentuhan pada bola. Kasus ini berbanding terbalik dengan hasil yang ditemukan oleh Arslan et al. (2020), bahwa periode pelatihan SSG selama 5 minggu dapat meningkatkan agility. Sedangkan pada metode drill yang diterapkan juga tidak banyak memberikan kesempatan pada siswa untuk melakukan sentuhan-sentuhan pada bola yang nantinya dapat meningkatkan ketrampilan dalam bermain. Berdasarkan hal tersebut, menarik untuk diselidiki, karena berdasarkan studi literatur yang dilakukan metode drill maupun metode SSG terbukti dapat meningkatkan keterampilan bermain dalam sepakbola dengan kaunggulan dan juga kelemahan masing-masing. Namun, pada kedua metode yang digunakan tersebut, dalam latihan keterampilan sepakbola memiliki kekurangan pada subjek yang akan diteliti. Proses latihan berlangsung kurang optimal kepada seluruh siswa dikarenakan siswa memiliki agility yang berbeda-beda. Sedangkan siswa memerlukan agility untuk mendukung berbagai gerak dalam sepakbola. Siswa memerlukan agility untuk berpartisipasi aktif dalam latihan. Seperti yang dikemukakan oleh Turner dan Stewart, (2014), bahwa kelincahan adalah salah salah satu komponen biomotor utama dalam mendukung performa pemain sepakbola. Dengan kelincahan, pemain mampu untuk mengubah arah, memulai dan berhenti dengan cepat baik dalam pertandingan maupun latihan sepakbola (Little \& Williams, 2006). Adapun pada penelitian ini permasalahan dibatasi pada pengaruh metode latihan dan agility terhadap keterampilan sepakbola.

Berdasarkan permasalahan yang telah kami paparkan, penelitian ini bertujuan untuk membandingan penggunaan metode pelatihan small-sided games (SSG) dengan Drill (tradisional), metode pelatihan mana yang sesuai dengan individu kurang baik dalam keterampilan gerak dan metode mana yang sesuai untuk individu yang memiliki keterampilan gerak yang baik. Penelitian ini didukung dengan perumusan pertanyaan penelitian: (1) bagaimana hubungan agility dengan keterampilan pada siswa SMA Kabupaten Bantul? (2) Bagaimana perbedaan pengaruh antara metode latihan drill dan metode SSG terhadap keterampilan sepakbola? (3) Bagaimana pengaruh agility tinggi dan rendah pada penggunaan metode pelatihan SSG dan Drill terhadap keterampilan sepakbola?

\section{METODE}

Jenis penelitian ini merupakan penelitian eksperimen dengan pendekatan kuantitatif. Desain penelitian menggunakan eksperimen faktorial 2x2. Masing-masing faktor terdiri dari dua buah taraf, dengan menggunakan tes awal (pre-test) dan tes akhir (post-test). Waktu penelitian dilaksanakan selama lima minggu dengan frekuensi pertemuan tiga kali dalam seminggu.

Teknik pengambilan sampel menggunakan purposive random sampling yang kemudian terpilih 60 siswa sebagai partisipan penelitian. Pengukuran agility dilakukan untuk menentukan jumlah sampel di kelompok treatment. Hasil pengukuran agility dinilai berdasarkan klasifikasi tingkat agility pada tabel Illinois Agility Run Test (MacKenzie, 2015), yaitu excellent (istimewa), above average (di atas rata-rata), average (rata-rata), bellow average (di bawah rata-rata) dan poor (rendah). Sedangkan tes keterampilan bermain sepakbola menggunakan The David Lee Soccer Potential Circuit Test (Australian Soccer Federation et al., 1979) (lihat Gambar 1.) dengan ketentuan umum sebelum pelaksanaan tes, tidak ada percobaan untuk subjek, sebelum melakukan tes, subjek melakukan pemanasan selama 5-10 menit.

Teknik analisis data yang digunakan adalah statistik parametrik berupa analisis variansi dua jalur (Two-Way Anova) dan uji lanjutnya (Post-Hoc Tests) dengan LSD (Least Square Difference). Mengingat analisis data penelitian dilakukan dengan menggunakan ANAVA, maka terlebih dahulu dilakukan uji normalitas dan homogenitas data. Teknik yang digunakan dalam uji normalitas adalah uji Kolmogorov Smirnov. Pengujian hipotesis penelitian dilakukan dengan menggunakan ANOVA yaitu dengan uji taraf signifikansi $5 \%$ atau 0,05. Uji ini dilakukan untuk mengetahui perbedaan rerata nilai hasil peningkatan antara pretest dan posttest pada kelompok eksperimen dan mengetahui interaksi antara metode latihan dan agility terhadap keterampilan bermain sepakbola. Setelah dilakukan analisi variansi dan terjadi interaksi yang signifikan maka dilanjutkan menggunakan analisis perbandingan Post-Hoc Tests dengan LSD (Least Square Difference) untuk mengetahui perlakuan yang paling efektif meningkatkan keterampilan bermain sepakbola. 
Sepakbola, 1 (1), 2021, 26

Prahastara Prahastara, FX. Sugiyanto

Keseluruhan proses perhitungan statistik menggunakan bantuan komputer software SPSS versi ke 26 (IBM, 2020).

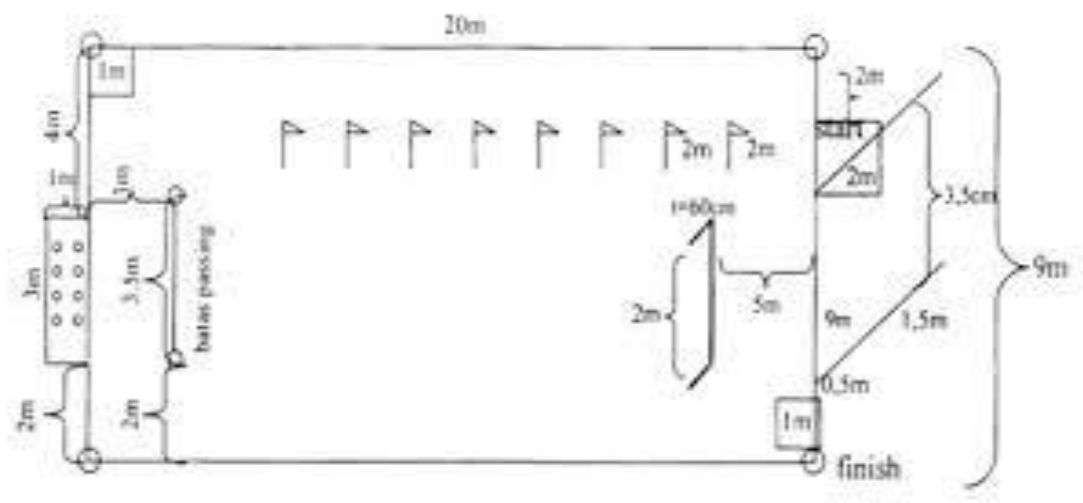

Gambar 1. Ball Technique The David Lee Soccer Potential Circuit Test (Australian Soccer Federation et al., 1979)

\section{HASIL DAN PEMBAHASAN}

\section{Agility}

Berdasarkan analisis statistik uji normalitas yang telah dilakukan dengan menggunakan uji Z Kolmogorov Smirnov, data pretest dan posttest keterampilan sepakbola pada siswa ekstrakurikuler sepakbola yang memiliki agility tinggi kelompok metode latihan drill (A1B1) terdapat tingkat signifikasi sebesar 0,733 dan 0,858 . Hal ini berarti $\mathrm{p}>0,05$ yang berarti bahwa $\mathrm{H}_{0}$ diterima dan Ha ditolak (berdistribusi normal). Kemudian data pretest dan posttest keterampilan sepakbola pada siswa ekstrakurikuler sepakbola yang memiliki agility rendah kelompok metode latihan drill (A1B2) terdapat tingkat signifikasi sebesar 0,647 dan 0,725. Hal ini berarti $p>0,05$ yang berarti bahwa $\mathrm{H}_{0}$ diterima dan Ha ditolak (berdistribusi normal).

Sedangkan pada data pretest dan posttest keterampilan sepakbola pada siswa ekstrakurikuler sepakbola yang memiliki agility tinggi kelompok metode latihan small sided games (A2B1) terdapat tingkat signifikasi sebesar 0,779 dan 0,632 . Hal ini berarti $p>0,05$ yang berarti bahwa $\mathrm{H}_{0}$ diterima dan Ha ditolak (berdistribusi normal). Selanjutnya pada data pretest dan posttest keterampilan sepakbola pada siswa ekstrakurikuler sepakbola yang memiliki agility rendah kelompok metode latihan small sided games (A2B2) terdapat tingkat signifikasi sebesar 0,560 dan 0,657 . Hal ini berarti $\mathrm{p}>0,05$, yang berarti bahwa $\mathrm{H}_{0}$ diterima dan Ha ditolak (berdistribusi normal). Artinya data pada tes awal setiap kelompok terbukti berdistribusi normal dan telah memenuhi uji prasayarat.

Tabel 1. Perbedaan Hasil Pengukuran Tingkat Agility

\begin{tabular}{ccccccc}
\hline \multirow{2}{*}{ Statistik } & \multicolumn{3}{c}{ Agility Tinggi } & \multicolumn{3}{c}{ Agility Rendah } \\
\cline { 2 - 6 } & Pretest & Posttest & Selisih & Pretest & Posttest & Selisih \\
\hline Jumlah & 687,2 & 649,84 & 37,40 & 933,52 & 906,32 & 27,20 \\
Rata-rata & 24,54 & 23,96 & 1,34 & 29,17 & 28,32 & 0,85 \\
\hline
\end{tabular}

Berdasarkan analisis statistik uji homogenitas yang telah dilakukan dengan menggunakan uji Levene Test, diperoleh nilai signifikasi pada pretest dan posttest keterampilan sepakbola kelompok drill sebesar 0,104 dan 0,106 >0,05. Hal ini berarti dalam kelompok data pada pretest dan posttest keterampilan sepakbola kelompok drill memiliki varian yang homogen. Demikian juga dengan hasil perhitungan pada pretest dan posttest keterampilan sepakbola kelompok small sided games diperoleh nilai signifikasi sebesar 0,109 dan 0,174 >0,05. Hal ini berarti dalam kelompok data memiliki varian yang homogen. Artinya data pada pretest dan posttest memiliki varian yang homogen dan telah memenuhi uji prasyarat analisis.

Berdasarkan dari hasil penelitian pada posttest menunjukkan bahwa agility tinggi memiliki pengaruh yang berbeda dengan agility rendah. Hal ini dibuktikan dari nilai signifikasi Univariate Test sebesar 0,000 $<0,05$, dengan demikian $\mathrm{H}_{02}$ ditolak karena angka signifikansi yang dihasilkan 
kurang dari 0,05. Berarti bahwa agility tinggi dan agility rendah memiliki pengaruh yang berbeda dapat diterima kebenarannya. Selisih rerata data pretest dan posttest, ternyata siswa agility tinggi memiliki rata-rata peningkatan sebesar 1,34 detik dan siswa agility rendah memiliki rata-rata peningkatan sebesar 0,85 detik. Sehingga pengaruh keterampilan sepakbola siswa yang memiliki agility tinggi lebih baik daripada siswa yang memiliki agility rendah, karena menghasilkan peningkatan waktu yang lebih baik. Hal tersebut diperkuat dengan pendapat menurut Holmberg, (2009) atlet yang terampil menghasilkan respon lebih cepat dan lebih akurat karena kemampuannya untuk mengambil isyarat tugas yang relevan dari lingkungannya meningkat. Kemudian peneliti lain mengatakan pemain sepakbola membutuhkan agility untuk dapat melakukan berbagai macam teknik keterampilan dan merubah kecepatan (Little \& Williams, 2006; Turner \& Stewart, 2014).

\section{Metode Latihan SSG dan Drill}

Berdasarkan dari hasil penelitian pada posttest menunjukkan bahwa metode latihan drill memiliki pengaruh yang berbeda dengan metode latihan small sided games (lihat Gambar 3). Hal ini dibuktikan dari nilai signifikasi Univariate Test sebesar $0,002<0,05$, dengan demikian $H_{01}$ ditolak karena angka signifikansi yang dihasilkan kurang dari 0,05. Berarti bahwa metode latihan drill dan metode latihan SSG memiliki pengaruh yang berbeda dapat diterima kebenarannya.

Selisih rerata data pretest dan posttest, ternyata metode latihan drill memiliki rata-rata peningkatan sebesar 0,57 detik dan metode latihan small sided games memiliki rata-rata peningkatan sebesar 1,58 detik. Sehingga kelompok siswa yang mendapatkan treatment metode latihan small sided games mempunyai peningkatan keterampilan sepakbola lebih baik daripada siswa yang diberikan treatment metode latihan drill.

Metode latihan drill dan metode latihan SSG mempunyai berbagai perbedaan dalam proses treatment yang dilakukan. Inti dari perbedaan antara metode latihan drill dan metode latihan SSG yaitu metode latihan drill dengan melakukan gerakan teknik secara berulang-ulang dengan tujuan agar terjadi otomatisasi gerakan, serta pelatih selalu mengoreksi agar perhatian tertuju pada kebenaran gerak. Sedangkan metode latihan small sided games dilakukan dengan model latihan yang mengajak siswa untuk bermain dengan materi latihannya, sehingga lebih mudah diterima.

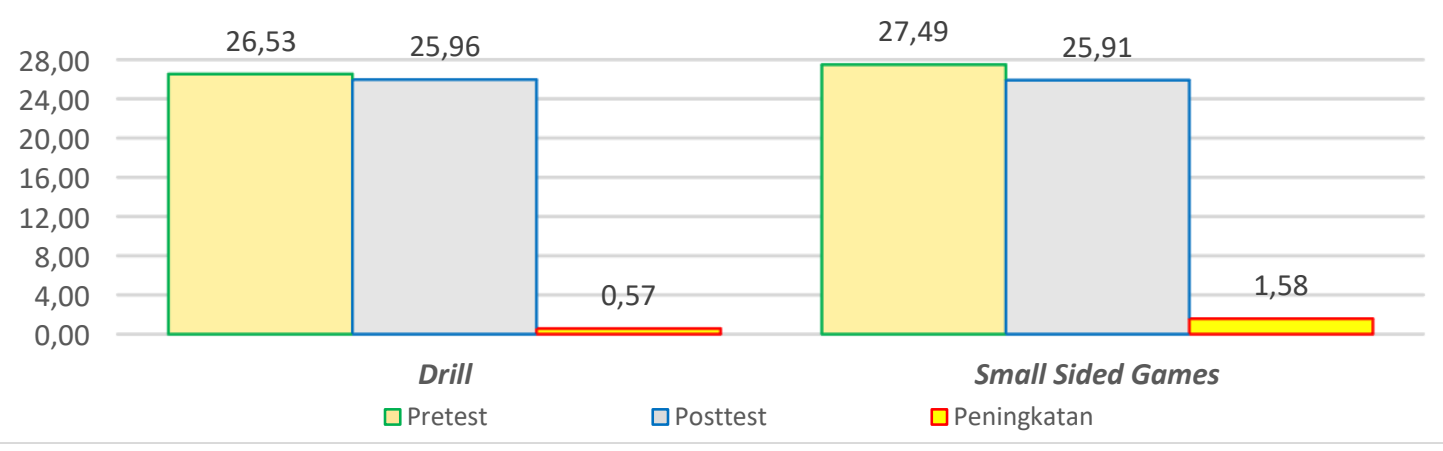

Gambar 2. Rata-Rata Keterampilan Sepakbola Tiap Kelompok Berdasarkan Metode Drill dan Metode SSG

\section{Pengaruh Agility pada Metode Latihan SSG dan Drill}

Berdasarkan nilai signifikasi Univariate Test sebesar 0,052 >0,05, dengan demikian $H_{03}$ diterima karena angka signifikansi yang dihasilkan lebih dari 0,05. Hal ini berarti bahwa agility tinggi dengan metode drill dan agility tinggi dengan metode small sided games tidak memiliki pengaruh yang berbeda terhadap keterampilan sepakbola dapat diterima kebenarannya. Siswa yang memiliki agility tinggi dengan metode latihan drill terbukti lebih baik daripada siswa yang memiliki agility rendah dengan rata-rata peningkatan sebesar 0,84 detik dan siswa agility tinggi dengan metode latihan small sided games memiliki rata-rata peningkatan 1,83 detik. Siswa yang memiliki agility tinggi dilatih dengan menggunakan dua metode latihan yang berbeda (metode latihan drill dan metode latihan small sided games) maka siswa yang memiliki agility tinggi dilatih dengan metode small sided games terbukti lebih baik daripada siswa yang memiliki agility tinggi 
dilatih dengan metode drill. Hal ini dikarenakan metode small sided games memiliki keuntungan lebih banyak mengambil keputusan dan keterlibatan dalam permainan.

Berdasarkan nilai signifikasi Univariate Test sebesar 0,52 >0,05, dengan demikian $\mathrm{H}_{04}$ diterima karena angka signifikansi yang dihasilkan lebih dari 0,05. Hal ini berarti bahwa agility rendah dengan metode drill dan agility rendah dengan metode small sided games tidak memiliki pengaruh yang berbeda terhadap keterampilan sepakbola. Siswa agility rendah dengan metode latihan drill memiliki rata-rata peningkatan sebesar 0,34 detik dan siswa agility rendah dengan metode latihan small sided games memiliki rata-rata peningkatan 1,36 detik. Hal ini berarti siswa agility rendah dengan metode latihan small sided games lebih baik daripada siswa agility rendah dengan metode latihan drill sebagai hasil latihan, karena menghasilkan peningkatan waktu yang lebih baik. Hal ini dikarenakan metode drill yang kurang mene-kankan pada pemberian kesempatan kepada siswa untuk berpikir, menganalisis, dan memutuskan sendiri, misalnya mengapa harus melakukan seperti diinstruksikan oleh pelatih. Meskipun metode latihan drill menghasilkan penguasaan dalam beberapa aspek teknis, pengalaman-pengalaman berupa situasi per-mainan (game situation) akan lebih bermanfaat dalam memahirkan skill teknis maupun taktis olahraga. Penguasaan keterampilan sepakbola menggunakan variasi latihan keterampilan gerak yang tidak direncanakan (situasional) lebih baik untuk belajar apabila dibandingkan dengan jenis kondisi latihan yang dilakukan dengan mengulang-ulang gerakan (latihan terstruktur).

Berdasarkan hasil perhitungan Tests of Between-Subjects Effects didapat bahwa taraf signifikansi sebesar $0,000<0,05$, hal ini menunjukkan bahwa tingkat signifikansi $5 \%$ ada pengaruh bersama antara metode latihan dan agility terhadap hasil keterampilan sepakbola. Hal ini ini berarti bahwa antara metode latihan (drill dan small sided games) dan agility terhadap hasil keterampilan sepakbola memiliki hasil interaksi. Setelah teruji terdapat interaksi antara metode latihan dan agility untuk meningkatkan hasil keterampilan sepakbola, maka perlu dilakukan uji lanjut dengan menggunakan Post Hoc Test. Berdasarkan tabel hasil perhitungan Multiple Comparisons pada tanda asteris $\left({ }^{*}\right)$ menunjukkan bahwa pasangan-pasangan yang memiliki interaksi secara nyata (signifikan) adalah: (1) A1B1 dengan A1B2; (2) A1B1 dengan A2B2; (3) A1B2 dengan A2B1; (4) A2B1 dengan A2B2.

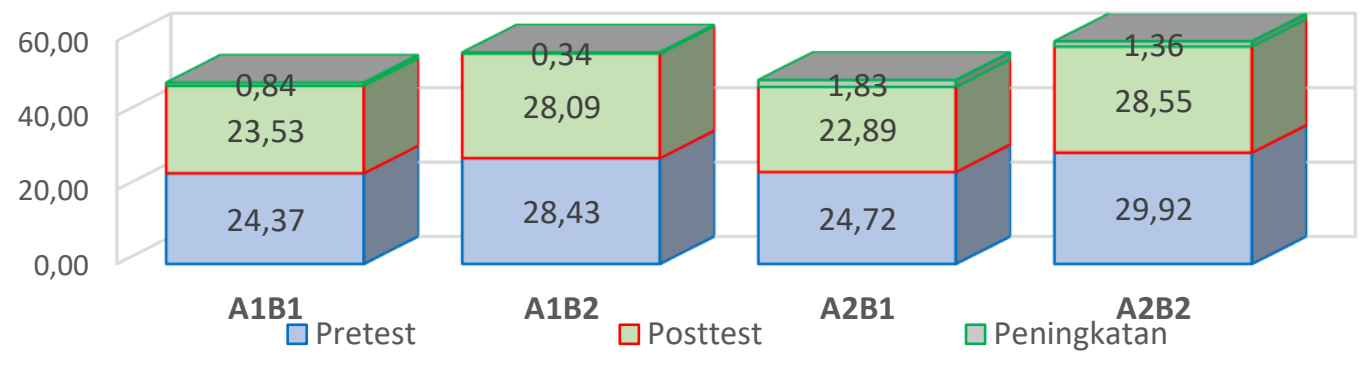

Gambar 3. Perbandingan Peningkatan Rata-Rata Keterampilan Sepakbola Kelompok Kombinasi Metode Latihan dan Agility

A1B1: Kelompok siswa ekstrakurikuler sepak-bola yang memiliki agility kategori tinggi dilatih menggunakan metode latihan drill.

A2B1: Kelompok siswa ekstrakurikuler sepak-bola yang memiliki agility kategori tinggi dilatih menggunakan metode latihan small sided games.

A1B2: Kelompok siswa ekstrakurikuler sepak-bola yang memiliki agility kategori rendah dilatih menggunakan metode latihan drill.

A2B2: Kelompok siswa ekstrakurikuler sepak-bola yang memiliki agility kategori rendah dilatih menggunakan metode latihan small sided games.

Jika kelompok metode latihan drill yang mempunyai agility tinggi dibandingkan dengan kelompok metode latihan drill yang memiliki agility rendah maka terdapat pengaruh yang signifikan terhadap hasil keterampilan sepakbola. Jika kelompok metode latihan drill yang memiliki agility kategori tinggi dibandingkan dengan kelompok metode latihan small sided games yang memiliki agility kategori rendah maka terdapat perbedaan pengaruh yang signifikan terhadap 
hasil keterampilan sepakbola. Jika kelompok metode latihan drill yang memiliki agility kategori rendah dibandingkan dengan kelompok metode latihan small sided games yang memiliki agility kategori tinggi maka terdapat perbedaan pengaruh yang signifikan terhadap hasil keterampilan sepakbola. Jika kelompok metode latihan small sided games yang memiliki agility kategori tinggi dibandingkan dengan kelompok metode latihan drill yang memiliki agility kategori rendah maka terdapat perbedaan pengaruh yang signifikan terhadap hasil keterampilan sepakbola.

Sedangkan pasangan-pasangan lainnya dinyatakan tidak memiliki interaksi adalah: (1) A1B1 dengan A2B1; (2) A1B2 dengan A2B2. Jika kelompok metode latihan drill yang mempunyai agility kategori tinggi dibandingkan dengan kelompok metode latihan small sided games yang memiliki agility kategori tinggi maka tidak terdapat pengaruh yang signifikan terhadap hasil keterampilan sepakbola. Jika kelompok metode latihan drill yang memiliki agility kategori rendah dibandingkan dengan kelompok metode latihan small sided games yang memiliki agility kategori rendah maka tidak terdapat perbedaan pengaruh yang signifikan terhadap keterampilan sepakbola.

Hasil analisis interaksi tersebut diketahui bahwa metode latihan drill lebih efektif digunakan untuk siswa yang memiliki agility kategori tinggi, sedangkan metode latihan small sided games lebih efektif digunakan untuk siswa yang memiliki agility kategori rendah. Hasil temuan ini diperkuat dengan pendapat (Farrow et al., 2013) di dalam pembelajaran penguasaan keterampilan meng-gunakan variasi latihan keterampilan gerak yang tidak direncanakan (situasional) lebih superior untuk belajar apabila dibandingkan dengan jenis kondisi latihan yang dilakukan dengan mengulang-ulang gerakan (latihan terstruktur). Penampilan pada kondisi latihan terstruktur lebih superior daripada kondisi latihan acak, tetapi hanya selama fase latihan pada saat perlakuan. Ketika atlet atau pembelajar diberi kesempatan sesaat untuk mengingat dan melakukan tes, hasilnya berkebalikan. Proses belajar lebih banyak terfasilitasi dengan latihan acak/situasional daripada latihan terstruktur.

Ditinjau dari pelaksanaannya, maka metode latihan drill akan cocok apabila digunakan untuk melatih siswa yang memiliki agility tinggi, sedangkan metode latihan small sided games akan cocok apabila digunakan untuk melatih siswa yang memiliki agility rendah. Hal ini karena dalam metode latihan drill bentuk latihannya sederhana sehingga siswa yang memiliki agility tinggi akan maksimal dalam melaksanakan pengulangan tugas gerak yang berkualitas. Sedangkan dalam metode latihan small sided games bentuk latihannya sangat kompleks sehingga siswa yang memiliki agility rendah akan terpacu untuk melakukan gerakan dengan mobilitas tinggi untuk meningkatkan agility.

\section{SIMPULAN}

Ada perbedaan pengaruh metode latihan drill dan metode latihan small-sided games terhadap keterampilan sepakbola, nilai $\mathrm{p}=0,002<0,05$. Metode latihan small sided games lebih baik daripada metode latihan drill untuk meningkatkan keterampilan sepakbola. Ada perbedaan keterampilan sepakbola siswa yang memiliki agility tinggi dan siswa yang memiliki agility rendah, nilai $\mathrm{p}=0,000<0,05$. Siswa yang memiliki agility tinggi mempengaruhi keterampilan sepakbola yang lebih baik daripada siswa yang memiliki agility rendah. Ada perbedaan pengaruh siswa yang memiliki agility tinggi dengan dan siswa yang memiliki agility rendah terhadap keterampilan sepakbola, nilai $\mathrm{p}=0,052>0,05$. Siswa yang memiliki agility tinggi dengan metode small sided games terbukti lebih baik daripada siswa siswa yang memiliki agility tinggi dilatih dengan metode drill. Ada perbedaan pengaruh siswa yang memiliki agility rendah terhadap keterampilan sepakbola, nilai $\mathrm{p}=0,524>0,05$. Siswa agility rendah dengan metode latihan small sided games lebih baik daripada siswa agility rendah dengan metode latihan drill. Ada interaksi antara metode latihan dan agility terhadap keterampilan sepakbola, nilai signifikansi Tests of Between-Subjects Effects sebesar 0,000 <0,05. Metode latihan drill akan cocok apabila digunakan untuk melatih siswa yang memiliki agility tinggi, sedangkan metode latihan small sided games akan cocok apabila digunakan untuk melatih siswa yang memiliki agility rendah. 
Sepakbola, 1 (1), 2021, 30

Prahastara Prahastara, FX. Sugiyanto

\section{DAFTAR PUSTAKA}

Arslan, E., Orer, G., \& Clemente, F. (2020). Running-based high-intensity interval training vs. small-sided game training programs: Effects on the physical performance, psychophysiological responses and technical skills in young soccer players. Biology of Sport, 37(2), 165-173. https://doi.org/10.5114/biolsport.2020.94237

Australian Soccer Federation, Worthington, E., \& Broken Hill Proprietary Company (Eds.). (1979). Coach's manual. Broken Hill Pty Co. and Australian Soccer Federation.

Bonney, N., Ball, K., Berry, J., \& Larkin, P. (2020). Effects of manipulating player numbers on technical and physical performances participating in an Australian football small-sided game. Journal of Sports Sciences, 38(21), 2430-2436. https://doi.org/10.1080/02640414.2020.1787697

Castelão, D., Garganta, J., Santos, R., \& Teoldo, I. (2014). Comparison of tactical behaviour and performance of youth soccer players in $3 \mathrm{v} 3$ and $5 \mathrm{v} 5$ small-sided games. International Journal of Performance Analysis in Sport, 14(3), 801-813. https://doi.org/10.1080/24748668.2014.11868759

Chaalali, A., Rouissi, M., Chtara, M., Owen, A., Bragazzi, N. L., Moalla, W., Chaouachi, A., Amri, M., \& Chamari, K. (2016). Agility training in young elite soccer players: Promising results compared to change of direction drills. Biology of Sport, 33(4), 345-351. https://doi.org/10.5604/20831862.1217924

Davids, K., Araújo, D., Correia, V., \& Vilar, L. (2013). How Small-Sided and Conditioned Games Enhance Acquisition of Movement and Decision-Making Skills: Exercise and Sport Sciences Reviews, 41(3), 154-161. https://doi.org/10.1097/JES.0b013e318292f3ec

Davids, K., Araujo, D., Hristovski, R., Passos, P., \& Chow, J. Y. (2012). Ecological dynamics and motor learning design in sport. In N. Hodges \& M. A. Williams (Eds.), Skill Acquisition in Sport: Research, Theory \& Practice, 2nd ed. (pp. 112-130). Routledge. https://www.routledge.com/Skill-Acquisition-in-Sport-Research-Theory-andPractice/Hodges-Williams/p/book/9780415607865

Farrow, D., Baker, J., \& MacMahon, C. (2013). Developing Sport Expertise: Researchers and Coaches Put Theory into Practice, second edition. Routledge.

Folgado, H., Bravo, J., Pereira, P., \& Sampaio, J. (2019). Towards the use of multidimensional performance indicators in football small-sided games: The effects of pitch orientation. Journal of Sports Sciences, 37(9), 1064-1071. https://doi.org/10.1080/02640414.2018.1543834

Holmberg, P. M. (2009). Agility Training for Experienced Athletes: A Dynamical Systems Approach: Strength and Conditioning Journal, 31(5), 73-78. https://doi.org/10.1519/SSC.0b013e3181b988f1

Hristovski, R., Davids, K., Araujo, D., \& Passos, P. (2011). Constraints-induced emergence of functional novelty in complex neurobiological systems: A basis for creativity in sport. Nonlinear Dynamics, Psychology, and Life Sciences, 15(2), 175-206.

IBM. (2020, December 7). IBM SPSS Statistics 26 [CT738,CT763,CT761,CT762]. https://www.ibm.com/support/pages/downloading-ibm-spss-statistics-26

Kelly, David. M., Gregson, W., Reilly, T., \& Drust, B. (2013). The Development of a Soccer-Specific Training Drill for Elite-Level Players: Journal of Strength and Conditioning Research, 27(4), 938-943. https://doi.org/10.1519/JSC.0b013e3182610b7d

Little, T., \& Williams, A. G. (2006). Suitability of Soccer Training Drills for Endurance Training. The Journal of Strength and Conditioning Research, 20(2), 316. https://doi.org/10.1519/R17094.1

Machado, G., Bach Padilha, M., González Víllora, S., Clemente, F. M., \& Teoldo, I. (2019). The effects of positional role on tactical behaviour in a four-a-side small-sided and conditioned soccer game. Kinesiology, 51(2), 261-270. https://doi.org/10.26582/k.51.2.15 
MacKenzie, B. (2015). 101 Performance Evaluation Tests. Green Star Media Limited.

Martens, R. (2004). Successful Coaching. Human Kinetics.

Sarmento, H., Clemente, F. M., Harper, L. D., Costa, I. T. da, Owen, A., \& Figueiredo, A. J. (2018). Small sided games in soccer - a systematic review. International Journal of Performance Analysis in Sport, 18(5), 693-749. https://doi.org/10.1080/24748668.2018.1517288

Tessitore, A., Meeusen, R., Piacentini, M. F., Demarie, S., \& Capranica, L. (2006). Physiological and technical aspects of "'6-a-side'” soccer drills. The Journal of Sports Medicine and Physical Fitness, 46(1), 36-43.

Turner, A. N., \& Stewart, P. F. (2014). Strength and Conditioning for Soccer Players: Strength and Conditioning Journal, 36(4), 1-13. https://doi.org/10.1519/SSC.0000000000000054

Wickens, C. D. (1989). Attention and skilled performance. In Human skills, 2nd ed (pp. 71-105). John Wiley \& Sons.

Yang, G., Leicht, A. S., Lago, C., \& Gómez, M.-Á. (2018). Key team physical and technical performance indicators indicative of team quality in the soccer Chinese super league. Research in Sports Medicine, 26(2), 158-167. https://doi.org/10.1080/15438627.2018.1431539

Young, W., \& Rogers, N. (2014). Effects of small-sided game and change-of-direction training on reactive agility and change-of-direction speed. Journal of Sports Sciences, 32(4), 307-314. https://doi.org/10.1080/02640414.2013.823230 